2001, 2008, and 2009. MMWR Morb Mortal Wkly Rep 2011;60: 243-248.

2. Fagan RP, Edwards JR, Park BJ, Fridkin SK, Magill SS. Incidence trends in pathogen-specific central line-associated bloodstream infections in US intensive care units. Infect Control Hosp Epidemiol 2013;36:893-899.

\section{Sustaining High Influenza Vaccination Compliance with a Mandatory Masking Program}

To the Editor-influenza's ability to behave unpredictably and create serious illness still conflicts with the fact that a safe, effective vaccine is underutilized in healthcare settings. This underutilization led to the development of vaccination programs that involve negative consequences for lack of vaccination, usually by either termination of employment or a mandatory masking requirement. ${ }^{1,2}$

In July 2011, we reported a successful vaccination campaign that achieved greater than $90 \%$ compliance across clinical and nonclinical entities in our diverse health system. ${ }^{3}$ The crux of our program was to crystallize a transparent, easily enforceable, and peer-pressured mandatory masking policy for those who chose to remain unvaccinated.

In 2012, the health system acquired 3 new acute care community hospitals with a total of 424 additional licensed beds. These hospitals ranged from 10 to 90 miles away from the main campus, and vaccination compliance rates approximated $60 \%$ at baseline. Each campus had a majority of private nonemployed physicians and a variety of electronic capabilities. The largest acquisition had a nursing union. One hos- pital was purchased just 3 months prior to the start of our flu campaign. Over this period of expansion, the health system grew from 12,363 employees to 19,985 , and all campuses were immediately expected to adopt our vaccination program across clinical and nonclinical entities.

Our mandate was originally accomplished by full transparency regarding who was vaccinated, clarity on the masking policy, and engagement of leadership. An electronic password-protected database was available to all managers, showing the date any staff member received their vaccine. Employee badges displayed an annual campaign theme-based sticker upon vaccination. A clear protocol defined who paid for the mask, how often the mask needed to be changed, and even how it was to be worn. Additionally, the influenza vaccination program decentralized vaccine supplies by providing complete flu kits to appointed team captains for every department. The kit included prefilled vaccine syringes, consent forms, and stickers.

For the newer hospital acquisitions, however, some of this could not be done. Manual processes of recordkeeping, education, and compliance statistics had to be relied upon. Weekly stat facts were disseminated along with a more visible poster campaign. Flu masking rounds were incorporated into rounds that leadership made on a variety of patient safety issues, with participants alternating between the assistant chief medical officer, chief medical officer, and chief nursing officer along with infection prevention and regulatory performance improvement personnel.

As initially reported, the first 2 years of our mandatory masking program increased vaccination compliance from the baseline of $47 \%$ to $90 \%$ (system-wide, 2009-2010) and $92 \%$ (system-wide, 2010-2011). These numbers included all aspects of the health system, including all acute care hospitals,

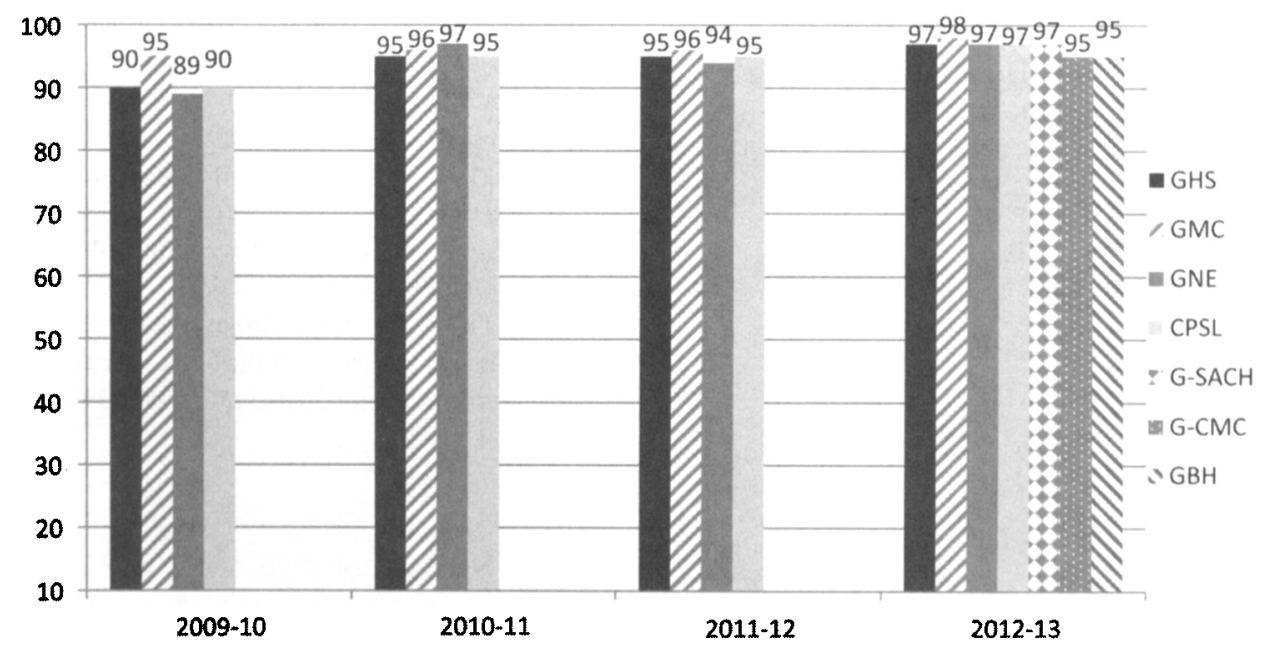

FIGURE 1. Influenza vaccination compliance rates, 2009-2013. CPSL, Community Practice Service Line; GBH, Geisinger Bloomsburg Hospital; G-CMC, Geisinger Community Medical Center; GHS, Geisinger Health System; GMC, Geisinger Medical Center; GNE, Geisinger Northeast; G-SACH, Geisinger Shamokin Area Community Hospital. 
community practice sites, ambulatory surgery centers, administrative buildings, and Geisinger's insurance company.

In subsequent years, these compliance rates continued to increase to $95 \%$ and ultimately $97 \%$ (Figure 1 ). The newer campuses (Geisinger-Bloomsburg Hospital, Geisinger-Community Medical Center, and Geisinger-Shamokin Area Community Hospital) achieved $95 \%-97 \%$ vaccination compliance the first year of acquisition (Figure 1). There were no legal challenges and no formal opposition to the program at any of the newer campuses. The final 2012-2013 compliance statistics for the health system, which grew to 19,985 employees, was $97 \%$. There were no terminations or disciplinary actions of any employees.

As is now widely known, attempts to improve vaccination compliance with educational programs did not achieve rates higher than about $40 \%{ }^{4,5}$ Informed declination improved compliance rates to approximately $60 \%-70 \% .{ }^{6}$ It is only with the advent of programs for which noncompliance resulted in a negative consequence (either job termination or compelled masking) that institutions began to achieve vaccination rates in excess of $90 \% .^{1-3}$ These compliance rates were comparable and statistically significant regardless of which consequence was employed.

Compelled vaccination programs have been promoted by several professional societies, including the Society for Healthcare Epidemiology (SHEA), but are not without some legal challenges. ${ }^{8}$ And while SHEA's position paper clearly endorses mandatory vaccination programs, regarding mandatory masking policies SHEA "believes there is potential utility for this strategy" but cites potential logistical issues with enforcement. ${ }^{9}$

What remained unclear, however, was whether both mandatory masking and mandatory vaccination programs could produce results that were equally sustainable and easily adaptable to all settings. Rakita et $\mathrm{al}^{2}$ showed consistently high vaccination compliance with a mandatory vaccine program over a 5-year period. Our data now shows sustainability over at least 4 years along with rapid adaptability in a variety of newly acquired community hospitals that were not acculturated to our health system and were at a significant distance away. This program was equally successful and adaptable to all nonclinical settings as well.

\section{ACKNOWLEDGMENTS}

We acknowledge Patricia Baylor, Diane Harlow, Lucy Ceresi, and Susan Lamont for assistance throughout the annual campaigns; Margaret Sharp for data collection; and all health service and wellness staff and all flu team captains for their tireless service.

Potential conflicts of interest. All authors report no conflicts of interest relevant to this article. All authors submitted the ICMJE Form for Disclosure of Potential Conflicts of Interest, and the conflicts that the editors consider relevant to this article are disclosed here.

Lisa M. Esolen, MD; ${ }^{1,2}$ Kimberly L. Kilheeney, BSN, COHN ${ }^{2}$

Affiliations: 1. Department of Infection Prevention and Control, Geisinger Health System, Danville, Pennsylvania; 2. Department of Health Services, Geisinger Health System, Danville, Pennsylvania.

Address correspondence to Lisa Esolen, MD, 100 North Academy Avenue, Danville, PA 17822 (lmesolen@geisinger.edu).

Infect Control Hosp Epidemiol 2014;35(5):603-604

(c) 2014 by The Society for Healthcare Epidemiology of America. All rights reserved. 0899-823X/2014/3505-0029\$15.00. DOI: $10.1086 / 675846$

\section{REFERENCES}

1. Babcock $\mathrm{H}$, Gemeinhart $\mathrm{N}$, Jones $\mathrm{M}$, et al. Mandatory influenza vaccination of health care workers: translating policy to practice. Clin Infect Dis 2010;50:459-464.

2. Rakita RM, Hagar BA, Crome P, Lammert JK. Mandatory influenza vaccination of healthcare workers: a 5-year study. Infect Control Hosp Epidemiol 2010;31(9):881-888.

3. Esolen LM, Kilheeney KL, Merkle RE, Bothe A. An alternate approach to improving healthcare worker influenza vaccination rates. Infect Control Hosp Epidemiol 2011;32(7):703-705.

4. Ofstead CL, Sherman BW, Wetzler HP, et al. Effectiveness of worksite interventions to increase influenza vaccination rates among employees and families. J Occup Environ Med 2013;55(2): 156-163.

5. Llupia A, Mena G, Olive V, et al. Evaluating influenza vaccination campaigns beyond coverage: a before-after study among health care workers. Am J Infect Control 2013;41:674-678.

6. Ribner BS, Hall C, Steinberg JP, et al. Use of a mandatory declination form in a program for influenza vaccination of healthcare workers. Infect Control Hosp Epidemiol 2008;29(4):302-308.

7. Nowalk MP, Lin $\mathrm{CH}$, Raymund M, Bialor J, Zimmerman RK. Impact of hospital policies on health care workers' influenza vaccination rates. Am J Infect Control 2013;41:697-701.

8. Stewart AM. Mandatory vaccination of health care workers. $N$ Engl J Med 2009;361:2015-2017.

9. Talbot TR, Babcock H, Caplan AL, et al. Revised SHEA position paper: influenza vaccination of healthcare personnel. Infect Control Hosp Epidemiol 2010;31(10):987-995. 